\title{
Myiasis on a Giant Squamous Cell Carcinoma of the Scalp: A Case Report and Review of Relevant Literature
}

\author{
Saptarshi Biswas ${ }^{\mathrm{a}, \mathrm{b}}$, Patrick McNerney ${ }^{\mathrm{a}}$
}

\begin{abstract}
Non-melanoma skin cancer is the most common malignancy amongst Caucasians worldwide with basal cell and squamous cell cancer being the most common. Giant skin cancers are a relatively rare type of skin cancer that are, by definition, greater than $5 \mathrm{~cm}$. This subtype by itself is associated with a significantly increased risk of complications and mortality. Myiasis is defined as infestation of body tissues of humans by dipterous larvae. Myiasis is often associated with malignant skin conditions. We describe a rare case of cutaneous myiasis located on a giant squamous cell carcinoma of the scalp in an elderly female. Myiasis coupled with malignant skin conditions provides a unique surgical challenge. This is especially true if the malignancy is invasive, as in our case, often requiring a multidisciplinary multimodality treatment plan.
\end{abstract}

Keywords: Myiasis; Scalp; Giant squamous cell cancer

\section{Introduction}

Infestation of body tissues of humans by dipterous larvae, known as myiasis, is an uncommon condition often found cutaneously in those with poor hygiene. The larvae will either be burrowed just under the skin, in a condition called furuncular myiasis, or in an open wound, in a condition known as wound myiasis [1]. Myiasis is also often associated with malignant conditions such as basal cell or squamous cell carcinoma (SCC) [2].

We describe a rare case of cutaneous myiasis located on a giant SCC of the scalp in an elderly female. Non-melanoma skin cancer (NMSC) is the most common malignancy amongst Caucasians worldwide [3]. The two major types of NMSC are

Manuscript accepted for publication June 03, 2016

aDepartment of Acute Care Surgery, Allegheny Health Network, Pittsburgh, PA, USA

${ }^{b}$ Corresponding Author: Saptarshi Biswas, Department of Acute Care Surgery, Forbes Regional Hospital, Allegheny Health Network, Pittsburgh, PA, USA. Email: Saptarshi.BISWAS@ahn.org

doi: http://dx.doi.org/10.14740/wjon966w basal cell carcinoma (BCC) and squamous cell carcinoma (SCC). Giant skin cancers are by definition greater than $5 \mathrm{~cm}$. These subtypes are associated with a significantly increased risk of complications and mortality [4-6]. These cancers also provide a surgical challenge especially if it is invasive, as in our case, and often involves a multidisciplinary multimodality treatment plan.

\section{Case Report}

A 95-year-old female presented to the emergency department with a scalp wound and myiasis. Patient had a history of type 2 diabetes mellitus, hypertension, hypothyroidism and a long standing BCC of the scalp (per the patient's family). Over the course of several months, the scalp lesion had grown larger. The patient presented with bleeding from the scalp lesion after local trauma secondary to a fall. The wound was left uncovered and the patient noticed the "maggots" a day later. The wound was circular in shape, approximately $5+\mathrm{cm}$ in its largest diameter with rolled edges infested by around 20 - 30 larvae.

Detailed physical examination performed during the initial emergency department visit showed no other abnormalities. Point of care labs obtained were within normal limits excluding a mild anemia. During this visit, all larvae were physically removed, and the wound was thoroughly irrigated first with saline and subsequently with peroxide. Dakins $1 / 2$ strength dressings were then applied.

The patient underwent a formal resection of the lesion with a $1 \mathrm{~cm}$ margin appropriate for an SCC of the size. All necrotic tissue, as well as the scalp lesion, was excised up to the level of the pericranium. Considering the advanced age of the patient, a decision was made not to do a split thickness skin graft (STSG) at this time. Instead an OASIS Wound Matrix was applied over the area to support tissue growth. OASIS ${ }^{\circledR}$ Wound Matrix, derived from porcine small intestinal submucosa, supports tissue regeneration in non-healing wounds by mimicking components of the human dermis extracellular matrix and contains collagens, GAGs, glycoproteins, and proteoglycans [7]. A wound vacuum was avoided so as not to promote angiogenesis in a cancer bed, instead a bolster was used to secure the OASIS graft in place. The patient tolerated the surgery well.

The specimen was analyzed using direct microscopy, hematoxylin and eosin (H\&E) stain, and chromogenic in situ 


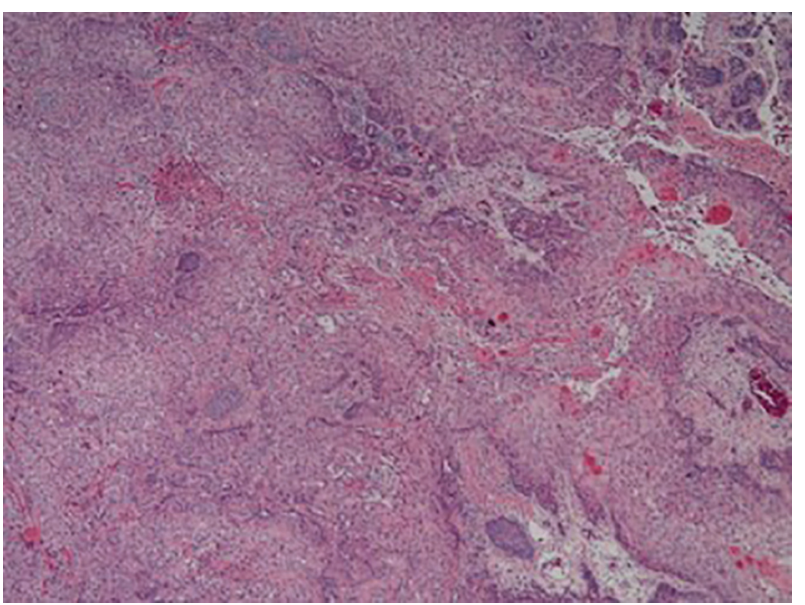

Figure 1. Low magnification. Invasive partially keratinized squamous cell carcinoma.

hybridization (CISH). The specimen was positive for partially keratinized ulcerative SCC of the scalp that was moderately differentiated and invasive, as seen in Figure 1. The tumor cells were described as large with irregular, atypical, hyperchromatic nuclei with nucleoli, which can be observed in Figure 2.

A follow-up clinic review a week later showed the wound to be clean, dry, and intact. The OASIS was noted to exhibit "excellent signs of uptake" that included a well-vascularized wound bed, with no signs of necrosis or drainage. The patient was referred for multidisciplinary review.

The patient was examined in the clinic a month later. This time the excised lesion grew in size with localized areas of abscess. The patient underwent incision and drainage along with debridement of necrotic tissue. The pathology was reported as invasive SCC of acantholytic type.

A metastatic workup was performed. CT scan of the soft tissue of the neck showed no neck masses or fluid collection. The CT was also negative for cervical lymphadenopathy. However, the CT of the chest did show the presence of a $1.8 \mathrm{~cm}$ left

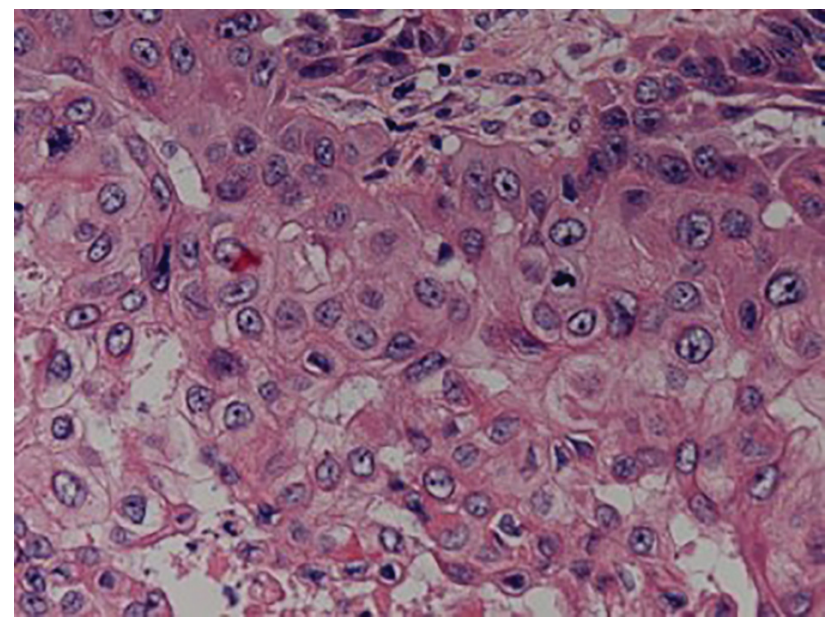

Figure 2. High power. Tumor cells are large with irregular, atypical, hyperchromatic nuclei with nucleoli. Few atypical mitosis in the background.

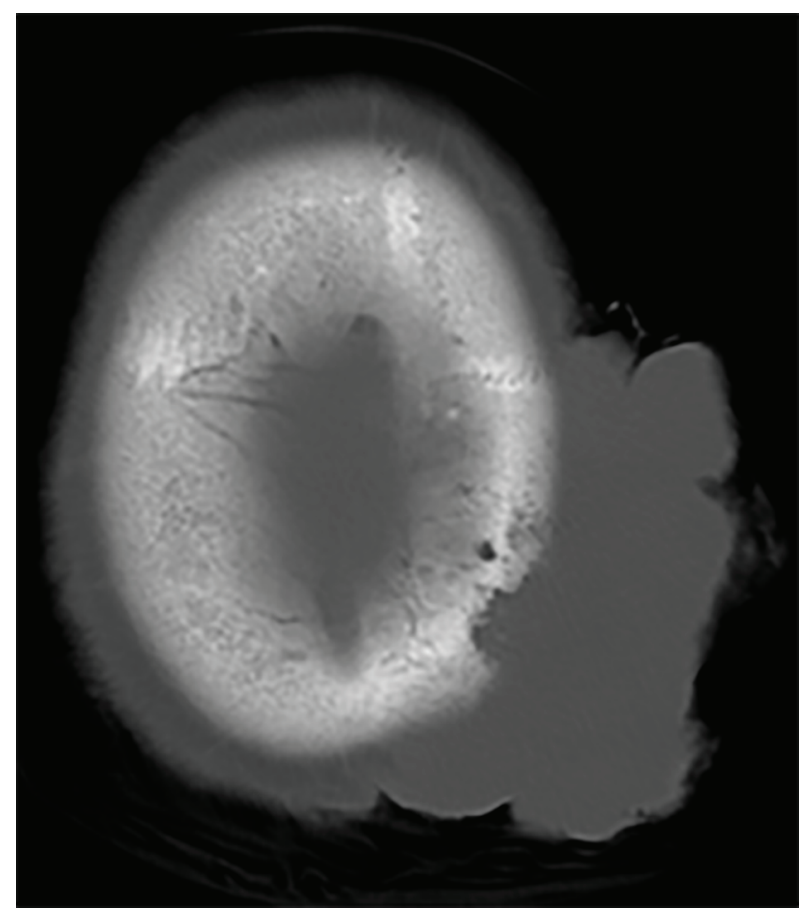

Figure 3. CT scan showing erosion of calvarium.

upper lobe pulmonary nodule. The provisional diagnoses were between metastasis versus a primary neoplasm. There was another lesion in the right upper lobe $2 \mathrm{~mm}$ in diameter which was essentially thought to be benign. Again the consensus was to follow conservatively the pulmonary lesions because of her advanced age and family discussion. A decision was then made for the patient to undergo radiation. Home health care was arranged for regular dressing changes.

The patient however was readmitted a month later with hypotension and generalized weakness and signs and symptoms of sepsis. She was empirically started on broad spectrum antibiotics and hemodynamic support. Due to her intricate history and guarded prognosis infectious disease, medical oncology, hematology, and palliative medicine were involved in her care. This time the scalp lesion had grown in size. CT and visual inspection showed a tumor with dimensions more than $7 \mathrm{~cm}$ with a raised summit of approximately $1.5 \mathrm{~cm}$ that was invading the calvarium, as seen in Figure 3 . The patient made a good recovery and is presently scheduled to undergo radiation of 5,000 - 6,000 cGy in 24 daily fractions. After informed discussion she was deemed unsuitable for aggressive chemotherapy.

\section{Discussion}

Myiasis is derived from a Greek word "mya", or fly, and was first proposed by Hope in 1840 to define human diseases caused by the larvae of Diptera [8,9]. Myiasis is usually classified based on entomological and clinical/anatomical point of view. Entomologically the causative flies can be largely divided into three myiasis producing groups: obligatory, fac- 
ultative, and accidental/pseudomyiasis. Clinical classification is based on their anatomical location [2]. Myiasis is classified into 1) sanguinivorous, or bloodsucking; 2) cutaneous myiasis, furuncular, and migratory; 3) wound myiasis; and 4) cavitary myiasis. This classification was used by Francesconi et al [2] based on Bishop's classification, who first proposed it in 1962, and later modified by James [10] and Zumpt [11]. Nosocomial myiasis attributed to myiasis in a hospital setting was first proposed by Jacobson in 1980 [8, 12].

Presentation of myiasis can vary significantly between these categories. The two broadest of these categories are cutaneous myiasis and cavitary myiasis [2]. Cavitary myiasis can occur in any internal orifice within the human body, but typical locations include urogenital, intestinal, tracheopulmonary, ophthalmological, cerebral, and various other ENT locations [13]. Cutaneous myiasis is another major category of myiasis and, as its name suggests, is confined to the skin [14]. Cutaneous myiasis is the far more common of the two forms and typical presents as either furuncular myiasis, which involves larval penetration within the skin giving a papule/pustule like appearance to the skin superior to the larva, or wound myiasis, which will typically present as an open wound with a number of clearly visible larvae within [14]. Migratory cutaneous myiasis is also possible. Myiasis is generally a clinical diagnosis, acquired via patient history and physical exam. The important risk factors for cutaneous or cavitary myiasis are poor hygiene, advanced age, alcoholics, chronic diseases such as diabetes mellitus and peripheral vascular diseases, psychiatric disorders and low socioeconomic status [15-21]. Certain infections, such as leprosy, are also associated with myiasis as are malignant wounds [2].

Wounds attributed to malignant conditions, usually BCC and SCC, have been found to be associated with myiasis [13]. Despite malignant wounds being known to be a predisposing factor for myiasis, myiasis is largely underreported [16]. Although a number of larvae species are found to be associated with myiasis, malignant wound myiasis is almost exclusively the result of infestation of larvae from Calliphorida and Sarcophagidae. Specifically, Lucilia sericata is the most common species identified in malignant wound maggot infestations. $L$. sericata is also known as the green bottle fly. Wollina et al in a brief report "Myiasis on squamous cell carcinoma of skin" reported three cases all associated with Lucilia spp. in a retrospective search from 2001 to 2014 [3]. In the same report, the author mentioned 12 other cases of SCC-associated myiasis due to different species.

This underrepresentation is likely the result of patient's psychological state of denial or avoidance of issues related to their oncologic condition [2]. Malignant conditions related to myiasis are most commonly those involving the skin, yet they have been found to be associated with a number of other malignancies as well, although less commonly [2]. These conditions include eccrine adnexal neoplasm, angiosarcoma, larynx carcinoma, breast cancers, Kaposi's sarcoma, melanoblastoma, non-Hodgkin's lymphoma, and cervical cancer [8, 22-29].

Malignant wounds result from cancerous invasion of lymph and blood vessels supporting the affected tissue [30]. Quality of life is a major concern in malignant wound management and often involves addressing the psychological effect a malignant wound can have on a patient [2]. Physical findings such as malodor, pain, and exudate can often result in severe psychological symptoms resulting in feelings of isolation [2]. Isolationism can result in worsening of wounds, demonstrated by myiasis in this case [2].

The goal of treatment is removal of larvae, treatment of secondary infections if present and surgical debridement if required [31]. Symptomatic improvement occurs immediately with the removal of the larvae. Such prompt action can obviate the need for antibiotics. The larvae in superficial wound myiasis can be removed with forceps. These larvae which are photophobic burrow deep into the tissues [16]. Localized asphyxia induced by various methods of wound occlusion will force these larvae to move out [16]. The options used to create occlusion are petroleum, animal fat, beeswax, butter, liquid paraffin, hair gel, nail polish, mineral oil and polymyxin B [2]. One percent lidocaine injection into deeper tissue planes and liquid nitrogen can also help in extraction [8]. In the presence of dead tissue, surgical exploration of the wound should be performed, larvae should be removed without cutting them and dead tissue should be debrided.

Initial surgical debridement of necrotic and malignant tissue is often preferred in cases associated with cutaneous wound malignancy, followed by pressure irrigation [31]. More advanced surgical techniques may be required for wound closure, depending on size and location of the malignant wound, seen by the use of a wound matrix in this case. Preferred treatment of myiasis requires removal of all visible larvae and possibly debridement of necrotic tissue [32]. This treatment can be complicated by tunneling of larvae away from the wound, and for this reason irrigation is often also recommended [2]. Use of $15 \%$ chloroform in olive oil can prevent tunneling as it has been found to paralyze larvae in certain instances [2, 33]. A solution of $1 \%$ ivermectin in propylene glycol is also a possible topical therapy [34]. Surgical extraction can be complemented with the use of systemic anti-helminth drugs, e.g. albendazole or ivermectin.

In situations where complicated anatomical structures are involved or removal by other means has been unsuccessful, surgical removal of the larvae may be required, though this is typically not the case [13]. Use of vacuum removal via venom extractors has even been employed in some scenarios where more typical modalities proved unsuccessful $[14,35]$.

SCC is the second most common cause of skin cancer, after BCC [36]. Cutaneous SCC (cSCC) originates from malignant proliferation of the keratinocytes of the epidermis [37, $38]$. Eighty to ninety percent of these cancers develop on the sun exposed areas of the head and neck and usually occur at sites of high cumulative chronic ultraviolet light exposure [38]. Malignant skin tumors rarely occur in the scalp but unless promptly diagnosed and treated appropriately, they can grow rapidly and infiltrate the underlying cranium, as in our case [37]. Lang et al recommend that scalp tumors, because of their high incidence of morbidity and mortality, be managed in an aggressive manner [39].

The size of the cSCC on initial diagnosis is significant as it is related to the prognosis. Increase of tumor size is associated with increased recurrence risk as well as regional lymph node metastases [40, 41]. Depth of invasion, histological differential 
grade, and presence of perineural and lymphovascular invasion are some of the anatomic-pathological criteria which need to be taken into account. Recurrence is also associated with regional metastasis. Patients with incomplete resection are also at increased risk of recurrence as in our case and subsequent regional metastasis $[41,42]$. Veness et al found $15 \%$ of recurrences in patients who had metastatic disease [43]. Huang and Boyce cited another study stating $50 \%$ of cSCC lesions with positive margins recurred with consequent increase in risk of metastases [44].

Complete surgical excision with histologically tumor free margins remains the ideal treatment option [45]. Alternatives like cryotherapy, photodynamic therapy and electrocoagulation are considered suboptimal in high risk cSCC [45-47]. There is no consensus concerning the use of selective sentinel node biopsy (SNB) in high risk cSCC. Some authors have advocated the use of SNB in immunocompromised patients, especially in cases that are poorly differentiated, recurrent, larger than $4 \mathrm{~cm}$ across, or those which arise in a chronic inflammatory lesion, scar tissue, etc. [48]. Radiation grossly yields poorer outcome compared to surgery in high risk cSCC and is usually reserved for elderly patients with inoperable tumors. High risk patients with perineural invasion, positive or indeterminate surgical margins, or in transit metastases benefit from adjuvant radiotherapy. Some chemotherapy agents have increased survival in high risk or locally advanced cSCC. Oral capecitabine or 5-fluorouracil (5-FU) has shown good results in the treatment of locally advanced cSCC [46]. Combination of 5-FU and subcutaneous interferon alpha for 2 - 3 weeks also has shown good results $[47,49]$. The EGFR inhibitor cetuximab has yielded encouraging results used alone or in combination with 5-FU and cisplatin, both with or without radiation therapy [47, 50-52].

Malignant scalp neoplasms which are aggressive enough to erode the bone and invade the cranial cavity are extremely rare $[2,38,39,53-59]$. The most common neoplasm in such a scenario is SCC, although there have been isolated reports of $\mathrm{BCC}$, basosquamous carcinoma, adnexal carcinoma, e.g., giant eccrine adenocarcinoma, familial cylindromatosis, Merkel carcinoma, Marjorin's ulcer, dermatofibrosarcoma, sebaceous carcinoma, and melanoma [37]. Such tumors cause extensive scalp ulceration invading the periosteum, subsequently eroding the underlying bone and extending into the cranial cavity. They may also eventually invade the dura mater and venous sinuses (e.g. sagittal sinus involvement) and often secondarily infected $[37,55,59]$. All reported cases had begun as growing ulcerative lesions which were neglected by the patients [37].

Scalp reconstruction can be challenging. A multidisciplinary approach including a neurosurgeon along with a plastic surgeon is often necessary to ensure safe tumor extirpation and effective reconstruction. In patients with extensive malignancies, like ours, survival takes precedence over function and esthetics $[60,61]$. Patients requiring radiation therapy present with added problems. STSG in these cases provide inadequate durability while staged procedures can delay adjuvant therapy [60]. Elderly patients, such as ours, often have poor surrounding tissue quality and often large defects are not amenable to primary or local flap closure [62]. Regional or free flaps may be a better option as they supply healthy tissue with their concomitant vascular supply and thus provides an optimal envi- ronment for tissue healing. This is particularly important in the scenario of radiotherapy. When all local options are exhausted trapezius, anterolateral thigh and latissimus dorsi flaps can be of use [60].

Our patient presented with a large fungating invasive SCC of the scalp despite previous resection. Current computer tomographic scan demonstrated a $(7 \times 5 \mathrm{~cm})$ lesion with bicortical calvarial involvement. Because of her advanced age and in accordance with a multidisciplinary team consensus involving the patient's family a decision was made to avoid any craniectomy and advanced flap closure in this patient.

\section{Conclusion}

Myiasis describes a group of disorders in which animal or human tissues serve as a host for the larvae of various dipterous flies, colloquially known as "maggots". The Diptera genera that commonly infest humans are Cochiliomyia (screwworm), Wohlfahrtia (flesh fly), Cordylobia (Tombu fly), and Dermatobia (botfly) [31]. This condition has a low incidence in temperate climates. We present an uncommon case of wound myiasis presenting itself as a complication of a neglected ulcerative SCC of the scalp. Besides being a giant cutaneous malignancy, this lesion had invaded the periosteum, and eroded the underling bone. We discuss the management options of such an uncommon case along with relevant literature review.

\section{Conflicts of Interest}

The authors declare that there is no conflict of interests regarding the publication of this paper.

\section{References}

1. Yebenes M, Munoz C, Sabat M, Palacio L, San Vicente B, Traveria FJ, Luelmo J. Multiple furunculoid myiasis on the scalp of a child. Dermatology Online Journal. 2007;13(2).

2. Francesconi F, Lupi O. Myiasis. Clin Microbiol Rev. 2012;25(1):79-105.

3. Wollina U, Bayyoud Y, Kronert C, Nowak A. Giant epithelial malignancies (Basal cell carcinoma, squamous cell carcinoma): a series of 20 tumors from a single center. $\mathrm{J}$ Cutan Aesthet Surg. 2012;5(1):12-19.

4. Archontaki M, Stavrianos SD, Korkolis DP, Arnogiannaki N, Vassiliadis V, Liapakis IE, Christ H, et al. Giant Basal cell carcinoma: clinicopathological analysis of 51 cases and review of the literature. Anticancer Res. 2009;29(7):2655-2663.

5. Lackey PL, Sargent LA, Wong L, Brzezienski M, Kennedy JW. Giant basal cell carcinoma surgical management and reconstructive challenges. Ann Plast Surg. 2007;58(3):250-254.

6. Thomas WO, Harper LL, Wong SG, Harris CN, Parker JA, Abernethy J, Murphy B, et al. Surgical management of giant nonmelanoma skin neoplasia. South Med J. 
1998;91(2):190-195.

7. OASIS ${ }^{\circledR}$ Matrix Products. Web. 27 Oct. 2015.

8. Nawin Kumar, Rajesh Parameshwaran Nair,Anuja Sinha, Amit Kumar. Myiasis in a case of invasive ductal carcinoma breast - A rare presentation. Med Res Chron. 2014;1(2) 208-2012.

9. Hope FW. On insects and their larvae occasionally found in the human body. Trans R Entomol Soc Lond. 1840;256271.

10. James MT. The flies that cause myiasis in man, U.S. Department of Agriculture miscellaneous publication no. 631. USDA, Washington DC.1947; p. 1-175.

11. Zumpt FKE. Myiasis in man and animals in the old world. London Butterworth. 1965:267.

12. Jacobson JA, Kolts RL, Conti M, Burke JP. Hospital-acquired myiasis. Infect Control. 1980;1(5):319-320.

13. Al-Maweri SA, Al-Sufyani GA, Tarakji B, Abdulrab S. Myiasis Associated with Oral Squamous Cell Carcinoma - A Literature Review. Asian Pac J Cancer Prev. 2015;16(12):4997-4999.

14. Hannam P, Khairnar K, Downey J, Powis J, Ralevski F, Pillai DR. Cutaneous myiasis in traveler returning from Ethiopia. Emerg Infect Dis. 2011;17(12):2385-2386.

15. Villwock JA, Harris TM. Head and neck myiasis, cutaneous malignancy, and infection: a case series and review of the literature. J Emerg Med. 2014;47(2):e37-41.

16. Raposo AA, Schettini AP, Massone C. Concurrent primary and secondary myiasis on basal cell carcinoma. An Bras Dermatol. 2012;87(2):292-295.

17. Rubio C, Ladron de Guevara C, Martin MA, Campos L, Quesada A, Casado M. [Cutaneous myiasis over tumorlesions: presentation of three cases]. Actas Dermosifiliogr. 2006;97(1):39-42.

18. Yeung JC, Chung CF, Lai JS. Orbital myiasis complicating squamous cell carcinoma of eyelid. Hong Kong Med J. 2010;16(1):63-65.

19. Abalo-Lojo JM, Lopez-Valladares MJ, Llovo J, Garcia A, Gonzalez F. Palpebro-orbital myiasis in a patient with basal cell carcinoma. Eur J Ophthalmol. 2009;19(4):683685.

20. Phillips WG, Marsden JR. Opportunistic cutaneous myiasis following radiotherapy for squamous cell carcinoma of the left temple. Br J Dermatol. 1993;129(4):502-503.

21. Sesterhenn AM, Pfutzner W, Braulke DM, Wiegand S, Werner JA, Taubert A. Cutaneous manifestation of myiasis in malignant wounds of the head and neck. Eur J Dermatol. 2009;19(1):64-68.

22. Ibrahim SF, Pryor J, Merritt RW, Scott G, Beck LA. Cutaneous myiasis arising in an eccrine adnexal neoplasm. Dermatol Online J. 2008;14(6):6.

23. Cheshier SH, Bababeygy SR, Higgins D, Parsonnet J, Huhn SL. Cerebral myiasis associated with angiosarcoma of the scalp: case report. Neurosurgery. 2007;61(1):E167; discussion E167.

24. Gopalakrishnan S, Srinivasan R, Saxena SK, Shanmugapriya J. Myiasis in different types of carcinoma cases in southern India. Indian J Med Microbiol. 2008;26(2):189192.

25. Kwong A, Yiu WK, Chow LW, Wong S. Chrysomya bezziana: a rare infestation of the breast. Breast $\mathrm{J}$. 2007;13(3):297-301.

26. Merino FJ, Campos A, Nebreda T, Canovas C, Cuezva F. [Cutaneous myiasis by Sarcophaga sp]. Enferm Infecc Microbiol Clin. 2000;18(1):19-21.

27. Minar J, Valkoun A. [Myiasis in a skin tumor]. Epidemiol Mikrobiol Imunol. 1998;47(1):32-34.

28. David S, Rupa V, Mathai E, Nair S. Non Hodgkins lymphoma of ethmoidal sinus with rhinoorbital myiasis. Indian J Cancer. 1996;33(4):171-172.

29. Wolfelschneider P, Wiedemann P. [External ophthalmic myiasis cause by Oestrus ovis (sheep and goat botfly)]. Klin Monbl Augenheilkd. 1996;209(4):256-258.

30. O'Brien C. Malignant wounds: managing odour. Can Fam Physician. 2012;58(3):272-274; e141-273.

31. Arbit E, Varon RE, Brem SS. Myiatic scalp and skull infection with diptera Sarcophaga: case report. Neurosurgery. 1986;18(3):361-362.

32. Biradar S, Wankhede P, Munde A, Shaikh S. Extensive Myiasis infestation associated with Oral Squamous Cell Carcinoma: Report of two cases. Dent Res J (Isfahan). 2015;12(1):100-105.

33. Weaver TL, McDonald C, Rosenthal A. Case Study-Deep Cutaneous Mass Excision Reveals an Unusual Finding. The Internet Journal of Allied Health Sciences and Practice. 2011;9(1).

34. Yadav Santosh Kumar. Extensive Myiasis Infestation over a Malignant Lesion in Maxillofacial Region Report of Cases. International Journal of Pharmaceutical \& Biological Archive. 2012;3(3).

35. MacFadden DR, Waller B, Wizen G, Boggild AK. Imported and locally acquired human myiasis in Canada: a report of two cases. CMAJ. 2015;187(4):272-275.

36. Marks R. Squamous cell carcinoma. Lancet. 1996;347(9003):735-738.

37. Selcuk Gocmen, Bilge Kagan Aysal, Ahmet Eroglu, Cihan Sahin, Fatih Uygur, Mehmet Nusret Demircan. Intracranial Extension of Squamous Cell Carcinoma of the Scalp: A Case Report. Journal of Neurological Sciences (Turkish). 2013;30(2):406-410.

38. Ahn JH, Abu-Serriah M, Ameerally P. Multiple synchronous cutaneous squamous cell carcinomas of the head and neck: a case report. J Oral Maxillofac Surg. 2011;69(10):e317-323.

39. Lang PG, Jr., Braun MA, Kwatra R. Aggressive squamous carcinomas of the scalp. Dermatol Surg. 2006;32(9):11631170.

40. Vasconcelos L, Melo JC, Miot HA, Marques ME, Abbade LP. Invasive head and neck cutaneous squamous cell carcinoma: clinical and histopathological characteristics, frequency of local recurrence and metastasis. An Bras Dermatol. 2014;89(4):562-568.

41. Cherpelis BS, Marcusen C, Lang PG. Prognostic factors for metastasis in squamous cell carcinoma of the skin. Dermatol Surg. 2002;28(3):268-273.

42. Rowe DE, Carroll RJ, Day CL, Jr. Prognostic factors for local recurrence, metastasis, and survival rates in squamous cell carcinoma of the skin, ear, and lip. Implications for treatment modality selection. J Am Acad Dermatol. 
1992;26(6):976-990.

43. Veness MJ, Palme CE, Morgan GJ. High-risk cutaneous squamous cell carcinoma of the head and neck: results from 266 treated patients with metastatic lymph node disease. Cancer. 2006;106(11):2389-2396.

44. Huang CC, Boyce SM. Surgical margins of excision for basal cell carcinoma and squamous cell carcinoma. Semin Cutan Med Surg. 2004;23(3):167-173.

45. Nuno-Gonzalez A, Vicente-Martin FJ, Pinedo-Moraleda F, Lopez-Estebaranz JL. High-risk cutaneous squamous cell carcinoma. Actas Dermosifiliogr. 2012;103(7):567578.

46. Garcia-Zuazaga J, Olbricht SM. Cutaneous squamous cell carcinoma. Adv Dermatol. 2008;24:33-57.

47. Amini S, Viera MH, Valins W, Berman B. Nonsurgical innovations in the treatment of nonmelanoma skin cancer. J Clin Aesthet Dermatol. 2010;3(6):20-34.

48. Toll-Abello A, Pujol-Vallverdu RM. Estudion del ganglio centinela en El cancer cutaneo no melanoma: situacion actual. Piel. 2006;21:127-134.

49. Jennings L, Schmults CD. Management of high-risk cutaneous squamous cell carcinoma. J Clin Aesthet Dermatol. 2010;3(4):39-48.

50. Bonner JA, Harari PM, Giralt J, Cohen RB, Jones CU, Sur RK, Raben D, et al. Radiotherapy plus cetuximab for locoregionally advanced head and neck cancer: 5-year survival data from a phase 3 randomised trial, and relation between cetuximab-induced rash and survival. Lancet Oncol. 2010;11(1):21-28.

51. Cranmer LD, Engelhardt C, Morgan SS. Treatment of unresectable and metastatic cutaneous squamous cell carcinoma. Oncologist. 2010;15(12):1320-1328.

52. Ruhstaller T, Pless M, Dietrich D, Kranzbuehler H, von Moos R, Moosmann P, et al. Cetuximab in combination with chemoradiotherapy before surgery in patients with resectable, locally advanced esophageal carcinoma: a prospective multicenter phase IB/II trial (SAKK75/06). J
Clin Oncol. 2011;29:26-31.

53. Abo Sedira M, Amin AA, Rifaat MA, El-Sebai HI, ElBadawy MA, Aboul Kassem HA. Locally advanced tumors of the scalp: the Egyptian National Cancer Institute experience. J Egypt Natl Canc Inst. 2006;18(3):250-257.

54. Denewer A, Khater A, Farouk O, Hegazy M, Mosbah M, Hafez M, Shahatto F, et al. Can we put a simplified algorithm for reconstruction of large scalp defects following tumor resection? World J Surg Oncol. 2011;9:129.

55. Etlik O, Bay A, Izmirli M, Ugras S, Yilmaz N, Turan A. Deep intracranial extension of squamous cell carcinoma of the scalp. Pediatr Blood Cancer. 2005;45(7):994-996.

56. Ferreira CP, Valle Hde A, Ferreira JA, Lima RB, Martins CJ. Giant squamous cell carcinoma in HIV-positive patient. Braz J Infect Dis. 2010;14(2):209-210.

57. Neubauer KE, Goldstein GD, Plumb SJ. Squamous cell carcinoma of the scalp in organ transplant recipients: exploring mechanisms for recurrence and treatment guidelines. Dermatol Surg. 2010;36(2):185-193.

58. Papadopoulos O, Frantzoglou M, Chrisostomidis C, Konofaos P, Frangoulis M, Barlas G. Neglected squamous cell carcinoma of the frontal area: a clinical report. J Craniofac Surg. 2006;17(5):1015-1020.

59. Soma PF, Chibbaro S, Makiese O, Marsella M, Diemidio P, Fricia M, Passanisi M, et al. Aggressive scalp carcinoma with intracranial extension: a multidisciplinary experience of 25 patients with long-term follow-up. J Clin Neurosci. 2008;15(9):988-992.

60. Kotamarti VS, Feintisch AM, Ciminello F. Invasive Squamous Cell Carcinoma of the Scalp. Eplasty. 2015;15:ic39.

61. Egemen O, Bingol D, Ozkaya O, Aksan T, Celik SE, Akan M. Use of scalp flaps as a salvage procedure in reconstruction of the large defects of head and neck region. Turk Neurosurg. 2012;22(6):712-717.

62. Prera E, Pfeiffer J. Galea-aponeurotic flap for the repair of large scalp defects extending to bone. Auris Nasus Larynx. 2015;42(2):156-159. 